Kansas State University Libraries

New Prairie Press

\title{
EVALUATION OF GENOTYPE BY ENVIRONMENT INTERACTIONS FROM UNREPLICATED MULTI-ENVIRONMENTAL TRIALS OF HYBRID MAIZE
}

Ani A. Elias

Kelly R. Robbins

Dev Niyogi

James J. Camberato

R. W. Doerge

See next page for additional authors

Follow this and additional works at: https://newprairiepress.org/agstatconference

Part of the Agriculture Commons, and the Applied Statistics Commons cc) (†) $\ominus$

This work is licensed under a Creative Commons Attribution-Noncommercial-No Derivative Works 4.0 License.

\section{Recommended Citation}

Elias, Ani A.; Robbins, Kelly R.; Niyogi, Dev; Camberato, James J.; Doerge, R. W.; and Tuinstra, Mitchell R. (2012). "EVALUATION OF GENOTYPE BY ENVIRONMENT INTERACTIONS FROM UNREPLICATED MULTIENVIRONMENTAL TRIALS OF HYBRID MAIZE," Conference on Applied Statistics in Agriculture. https://doi.org/10.4148/2475-7772.1024

This is brought to you for free and open access by the Conferences at New Prairie Press. It has been accepted for inclusion in Conference on Applied Statistics in Agriculture by an authorized administrator of New Prairie Press. For more information, please contact cads@k-state.edu. 


\section{Author Information}

Ani A. Elias, Kelly R. Robbins, Dev Niyogi, James J. Camberato, R. W. Doerge, and Mitchell R. Tuinstra 


\title{
EVALUATION OF GENOTYPE BY ENVIRONMENT INTERACTIONS FROM UNREPLICATED MULTI-ENVIRONMENTAL TRIALS OF HYBRID MAIZE
}

Ani A. Elias ${ }^{1}$, Kelly R. Robbins ${ }^{1,2}$, Dev Niyogi ${ }^{1,3}$, James J. Camberato ${ }^{1}$, R.W. Doerge ${ }^{1,4,}{ }^{*}$, and Mitchell R. Tuinstra ${ }^{1}$

${ }^{1}$ Department of Agronomy, Purdue University, West Lafayette, IN; ${ }^{2}$ Dow AgroSciences, Indianapolis, IN; ${ }^{3}$ Department of Earth and Atmospheric Sciences, Purdue University, West Lafayette, IN; ${ }^{4}$ Department of Statistics, Purdue University, West Lafayette, IN

*Corresponding author

\begin{abstract}
Diverse soils and varying weather conditions not only affect overall performance of hybrid maize in multi-environment field studies, but can also cause strong genotype by environment interactions (GEI). Modern maize breeding experiments utilize multilocation trials with augmented field designs to evaluate the performance of unreplicated test hybrids. Augmented designs are resource efficient; however, these designs do not efficiently quantify or test GEI variation in the test hybrids. New methods are being developed that use random regression models to incorporate multiple environmental effects into GEI models to increase their accuracy and predictive ability. Incorporation of varying weather and soil physical variables into these models can be used to determine the potential causal factors of GEI. The identification of causal factors can assist in developing clusters of locations where homogenous performance of hybrids can be expected. The utility of the proposed approach is demonstrated with a real data analysis.
\end{abstract}

Keywords: genotype by environment interaction, hybrid maize, multi-environment trial, augmented unreplicated design, environmental variables, random regression models. 


\section{Introduction}

Maize (Zea mays L.- common name: corn) is the most widely cultivated cereal food crop in the United States of America and is globally ranked first in production with approximately 316 million metric tons (MT) in USA and 844 million MT globally (FAO, 2009). Maize hybridizes freely (Martin, 1989) and productivity is substantially improved in hybrids as a result of heterosis. Hybrid performance is influenced by the environment and genotype by environment interactions (GEI) are common for agronomically important traits.

GEI are a challenge to plant breeders, agronomists, and crop producers because of the difficulties in selecting genotypes that perform well over diverse environments (Kang and Gorman, 1989). Understanding GEI and quantification of the resulting variation in response of crops would help to understand the genotypic characteristics in establishing breeding objectives, identify superior genotypes and their suitable environmental conditions, and establish better crop management practices (Signor et al., 2001; Yan and Hunt, 2001). Therefore, the cause and nature of significant GEI should be carefully considered before selecting the genotype (Gauch and Zobel, 1996; Kang and Gorman, 1989) for a particular environment.

To understand the extent of influence of environment and GEI, newly developed hybrids need to be tested in diverse environments before their commercial release into a particular target environment. Multi-environment trials (MET) are being utilized in such scenarios that eventually help in selecting the most suitable genotypes (Smith et al., 2005) for an environment. Based on MET, specific and broad adaptation of genotypes to environments can be illustrated.

In order to better understand GEI from MET, it is important to understand the phenology of maize in relation to local environments. Generally, thermal units (Warrington and Kanemasu, 1983) are used for determining the phenology of maize, especially by considering temperature and maturity rate. In this study, growing degree days (GDD) (Dwyer et al., 1999) are utilized for calculating heat sums and their relation to the phenology of maize. The GDD measurement can be utilized for the timing of a particular phenological event, and suitability of the hybrid to a particular environment (Warrington and Kanemasu, 1983). Analyzing the external environmental variables such as temperature, solar radiation, precipitation, and water holding capacity during various phenological phases helps to identify the potential causal factors of GEI (Signor et al., 2001). These potential causal factors for GEI will help in categorizing genotypes for specific environments in which they can be adapted for better and more homogenous performance. Linking a phenological and statistical understanding of the hybrids has potential to assist the categorization of genotypes for specific or broad adaptations to the environment.

Historically, the first statistical method for partitioning and analyzing GEI from MET was a simple linear regression (LR) of individual genotype performance over environmental means. Although this approach depicts estimated regression lines for each genotype, and the heterogeneity of the lines illustrates interactions (Eberhart and Russell, 1966; Finlay and Wilkinson, 1963), it fails to explain a large proportion of variation due to GEI, even when the main effects are explained effectively (Gauch, 1992). In order to effectively address the interaction term, a specific statistical model (Zobel et al., 1988) is required. 
Modifications to the LR models for complex GEI (Piepho, 1997; Smith et al., 2001) come in the form of multiplicative models, such as an Additive Main effect and Multiplicative Interactive model (AMMI) (Zobel et al., 1988), Shifted Multiplicative Model (SHMM) (Gauch, 1992), and Sites Regression Model (SREG or GGE) (Cornelius et al., 1996). In these models, GEI is partitioned by way of multivariate techniques, thus offering more insight in understanding and interpreting GEI compared to Analysis of Variance (ANOVA) and LR models. The multiplicative terms in these models partition GEI (or Genotype main effect (G) + GEI) into more than one dimension when subsetting genotypes into homogenous groups of environments. Later, mixed model versions of these multiplicative models have also been developed for the analysis of GEI (Piepho, 1997; Smith et al., 2001). These models have been extended by incorporating a large number of external variables (genotypic and environmental) for interpreting the potential causes of GEI. The two most commonly used models are factorial regression (FR) (Baril, 1992; van Eeuwijk et al., 1995), and partial least square regression (PLSR) models (Aastveit and Martens, 1986).

Although extensive work has been done on GEI methods, there are limitations in applying them to modern plant breeding evaluation techniques that use augmented field designs with unreplicated test hybrids (newly developed hybrids) in MET (Federer, 1961). Based on the statistical models developed (Federer, 1961; Federer, 2002; Federer and Raghavarao, 1975; Williams and John, 2003) for the estimation of GEI from augmented field designs, the check hybrids (controls) can be utilized for local error estimates and adjusted estimates for test hybrids used for genotypic and environmental effects nested within an environment (Federer et al., 2001). Unfortunately, these methods do not take complete advantage of the variation among test hybrids, possible relationships among locations, and also do not explore any underlying structure within the observed GEI that can explain the potential causes.

We developed nested random regression models (NRRMs), an extension of random regression models (Henderson, 1982), for field designs augmented with unreplicated test hybrids. An estimate of genotypic and environmental effect of test hybrids is obtained independently from check hybrids. In addition, estimates obtained for hybrids are not nested to particular locations, but are a function of hybrids across locations (by utilizing the possible relationship among locations). NRRMs can be used to predict the performance of genotypes on modified environmental variables. NRRMs can be implemented in two steps. First, principal component analysis (PCA) is utilized for partitioning weather variables into orthogonal principal components (PC). Second, PCs and other environmental indices are incorporated into NRRMs in order to estimate the variance caused by GEI to identify the potential causes of the variation. The candidate environmental indices from NRRMs can then be utilized in clustering the locations into homogeneous regions. This helps in allocating hybrids to regions producing maximum homogenous yield which eventually would increase the net production across the cropping regions. The NRRMs provide a more powerful tool for dissecting GEI and improving the efficiency of breeding programs when compared to the existing methods for analyzing GEI in augmented unreplicated field designs for MET. 


\section{Methods}

Phenology and phases of crop development

Since the yield response of maize depends on its phenology, GDD is used as the criteria for partitioning crop development. Based on GDD, crop development is partitioned into phases with an increment of 100 GDD centering on tasseling (flowering) and silking (fertilization) stages of the crop. That is, the crop life is partitioned into phases starting from tasseling back to planting and silking to harvesting phases with an increment of 100 GDD on either side.

\section{Environmental indices}

A large number of variables represent the daily weather data measurements. However, not all of them can be used directly in the model. PCA is performed using proc princomp procedure in SAS 9.2 version, and is used to reduce the dimension of the standardized weather relationship matrix. All of the PCs are utilized in model development irrespective of the amount of variation explained by their corresponding eigenvalues. In addition to PCs, raw physical soil variables collected from each location are also used in the models as environmental indices.

\section{Structure of NRRM models}

General structure NRRMs that include an interaction term are developed and then compared to a base model,

$$
\begin{aligned}
& y_{i j}=\mu+\beta_{i}+\alpha_{j}+\varepsilon_{i j} \\
& y_{i j}=\mu+\beta_{i}+\alpha_{0 j}+V_{k} * \alpha_{k j}+\varepsilon_{i j}
\end{aligned}
$$

(Base model)

(NRRMs)

where, $y_{i j}$ is the response variable (yield); $\mu$ is the overall mean; $\beta_{i}$ is the location effect for the $\mathrm{i}^{\text {th }}$ location, $\beta_{i} \sim \mathrm{N}\left(0, \sigma_{\beta}^{2}\right) ; \alpha_{j}$ is the genotype effect for the $\mathrm{j}^{\text {th }}$ genotype, $\alpha_{j} \sim \mathrm{N}\left(0, \sigma_{\alpha}^{2}\right) ; \alpha_{0 \mathrm{j}}$ is the intercept of the random regression of environmental index $V_{\mathrm{k}}$ on the $\mathrm{j}^{\text {th }}$ genotype; $\alpha_{\mathrm{k} j}$ is the regression coefficient for the random regression of environmental index on the $\mathrm{j}^{\text {th }}$ genotype; $\varepsilon_{\mathrm{ij}}$ is the experimental error, $\varepsilon_{\mathrm{ij}} \sim \mathrm{N}\left(0, \sigma^{2}\right)$.

$$
\left[\begin{array}{l}
\alpha_{0 j} \\
\alpha_{k j}
\end{array}\right] \sim \operatorname{MVN}\left(\left[\begin{array}{l}
0 \\
0
\end{array}\right],\left[\begin{array}{cc}
\sigma_{\alpha_{0}}^{2} & \sigma_{\alpha_{0}, \alpha_{k}} \\
& \sigma_{\alpha_{k}}^{2}
\end{array}\right]\right)
$$

Genotypes and locations are treated as random effects representing the number of levels in these variables. This also compensates for the lack of replication of genotypes in individual locations. Additionally, in NRRMs for estimation of G and GEI across locations, each genotype has a random effect for intercept and interaction terms which is nested within the whole data and environmental index matrix. If there are multiple indices, a unique combination of variables is used for fitting the models. All models are analyzed using the package 'lme4' in R/2.14.0 (Bates and Maechler, 2010). 


\section{Evaluation and choice of NRRMs}

Evaluation and selection of the most appropriate NRRMs is performed in four steps. First, candidate models from the simplest (using one environmental index) NRRMs are selected based on goodness of fit after being compared to the base model using Akaike Information Criterion (AIC) (Dayton, 2003). Second, the selected candidate models (NRRMs with lower AIC values) are assessed for the predictive performance using the leave-one-out cross validation technique (LOO-CV) (Brown, 2000). In LOO-CV, the dataset is divided into training and test datasets, and the models are fit on the training dataset. Solutions for the regression intercept and interaction coefficients of genotypes obtained from these analyses are utilized to calculate the estimate of the yield from the test dataset. Third, the estimated values are tested for correlation against the response values (yield) in the test dataset. Repetition of LOO-CV is performed as many times as there are number of locations, and thus every location is represented once in the test data. An average of the correlations for a particular model across all the test data is then calculate and compared to that of the base model. The NRRMs that exhibit an averaged correlation higher than that of the base model are filtered out. Fourth, the number of environmental indices is increased in NRRMs, and the steps one to three are repeated. At this stage, the third step is performed with a modification that correlation values are compared not just to that of base model but also to that of previous reduced NRRMs (i.e., NRRMs with lower number of environmental indices). The fourth step is repeated until the most appropriate family of NRRMs is selected. Based on the information from the final selected models, the environmental indices, specifically from a particular phase of the crop, are chosen as potential indicators of GEI.

\section{Real Data Analysis}

\section{Data}

The NRRMs are tested on real data obtained from unreplicated MET of maize hybrids conducted by Dow AgroSciences across the middle part of the United States Corn Belt in Wisconsin, Illinois, Iowa, and Indiana (Figure 1). The MET conducted in year 2009 consisted of 13 locations and 114 test hybrids. All hybrids were represented once in each location except for 12 hybrids that were represented only in 12 locations. A total of 1470 observations comprise the data. Daily weather and soil physical characteristics variables were collected (Table 1) from each of these locations starting from the planting to the harvesting stage of the crops. The crop development in each of these locations was classified into 21 phases centering on tasseling and silking stages based on the 100 GDD increment. There were 273 orthogonal PCs calculated from the weather information for each location used in the analysis. As the physical soil variables were onetime observations, those were used without any modifications. The response variable, crop yield, was obtained at the end of cropping period. The distribution of yield in each location is illustrated in Figure 2. The primary objective of this part of the analysis is to identify potential weather and soil indices that explain the potential for GEI.

\section{Models and output}

The process of identifying the indices responsible for GEI initiated with the utilization of the simplest NRRM (NRRMs-1.1), which are the NRRMs with one PC index variable. Thus, 
273 NRRMs-1.1 are assessed. A total of 173 indices are selected based on AIC values when compared to the base model. The number of indices is reduced to 22 based on evaluating the predictive performance of the models via LOO-CV. Simultaneously, 84 (variable) sets are calculated by the unique combination of three soil index variables at a time. These models are denoted by NRRMs-3.1 and compared to the base model. After LOO-CV, 12 NRRMs-3.1 candidate models are selected.

The selected indices from NRRMs-1.1 are included in NRRMs-1.2, where two variables can be incorporated simultaneously, after calculating all possible unique combination of 22 variables. AIC values from the 231 NRRMs- 1.2 are compared to those of the base model, and 208 of them are relatively smaller. The selected 208 NRRMs- 1.2 models are tested for predictive performance, even though none of them had AIC values lower than those of the candidate NRRMs-1.1. There are 36 models with higher predictability than that of the highest NRRMs1.1. Three of these models have higher predictability than NRRMs-3.1 (Figure 3). Additionally, the 22 selected PC indices from NRRMs-1.1 were combined with the 12 selected soil index sets from NRRMs-3.1, and thus 264 NRRMs-3.1.1 are assessed. After comparing the AIC values (Figure 4A) and predictive performance six NRRMs-3.1.1 are selected. Out of these six, two exhibited predicted the yield better than that of NRRMs-1.2 (Figure 4B). Since inclusion of more indices failed to provide any more information, the model selection process is terminated.

The final models selected were NRRMs-1.2 based on two PC indices, and NRRMs-3.1.1 which included three soil indices and one PC index. The models are represented as:

$$
y_{i j}=\mu+\beta_{i}+\alpha_{0 j}+V_{1} * \alpha_{1 j}+V_{2} * \alpha_{2 j}+\varepsilon_{i j}
$$

(NRRMs-1.2)

where, $y_{i j}$ is the response variable (yield); $\mu$ is the overall mean; $\beta_{i}$ is the location effect for the $\mathrm{i}^{\text {th }}$ location, $\beta_{i} \sim \mathrm{N}\left(0, \sigma_{\beta}^{2}\right) ; \alpha_{0 \mathrm{j}}$ is the intercept of the random regression of PC indices $V_{1}$, and $V_{2}$ on the $\mathrm{j}^{\text {th }}$ genotype; $\alpha_{1 j}$ is the regression coefficient for the random regression of PC index $V_{1}$ on the $\mathrm{j}^{\text {th }}$ genotype; $\alpha_{2 j}$ is the regression coefficient for the random regression of PC index $V_{2}$ on the $\mathrm{j}^{\text {th }}$ genotype; $\varepsilon_{\mathrm{ij}}$ is the experimental error, $\varepsilon_{\mathrm{ij}} \sim \mathrm{N}\left(0, \sigma^{2}\right)$.

$$
\begin{gathered}
{\left[\begin{array}{l}
\alpha_{0 j} \\
\alpha_{1 j} \\
\alpha_{2 j}
\end{array}\right] \sim \operatorname{MVN}\left(\left[\begin{array}{l}
0 \\
0 \\
0
\end{array}\right],\left[\begin{array}{ccc}
\sigma_{\alpha_{0}}^{2} & \sigma_{\alpha_{0}, \alpha_{1}} & \sigma_{\alpha_{0}, \alpha_{2}} \\
& \sigma_{\alpha_{1}}^{2} & \sigma_{\alpha_{1}, \alpha_{2}} \\
& & \sigma_{\alpha_{2}}^{2}
\end{array}\right]\right)} \\
y_{i j}=\mu+\beta_{i}+\alpha_{0 j}+V_{1} * \alpha_{1 j}+V_{2} * \alpha_{2 j}+V_{3} * \alpha_{3 j}+V_{4} * \alpha_{4 j}+\varepsilon_{i j}
\end{gathered}
$$

where, $\alpha_{0 \mathrm{j}}$ is the intercept of the random regression of $\mathrm{PC}$ and soil indices $V_{1}, V_{2}, V_{3}$, and $V_{4}$ on the $\mathrm{j}^{\text {th }}$ genotype; $\alpha_{2 j}$ is the regression coefficient for the random regression of soil index $V_{2}$ on the $\mathrm{j}^{\text {th }}$ genotype; $\alpha_{3 j}$ is the regression coefficient for the random regression of soil index $V_{3}$ on the $\mathrm{j}^{\text {th }}$ 
genotype; $\alpha_{4 j}$ is the regression coefficient for the random regression of soil index $V_{4}$ on the $\mathrm{j}^{\text {th }}$ genotype;

$$
\left[\begin{array}{c}
\alpha_{0 j} \\
\alpha_{1 j} \\
\alpha_{2 j} \\
\alpha_{3 j} \\
\alpha_{4 j}
\end{array}\right] \sim \operatorname{MVN}\left(\left[\begin{array}{l}
0 \\
0 \\
0 \\
0 \\
0
\end{array}\right],\left[\begin{array}{ccccc}
\sigma_{\alpha_{0}}^{2} & \sigma_{\alpha_{0}, \alpha_{1}} & \sigma_{\alpha_{0}, \alpha_{2}} & \sigma_{\alpha_{0}, \alpha_{3}} & \sigma_{\alpha_{0}, \alpha_{4}} \\
& \sigma_{\alpha_{1}}^{2} & \sigma_{\alpha_{1}, \alpha_{2}} & \sigma_{\alpha_{1}, \alpha_{3}} & \sigma_{\alpha_{1}, \alpha_{4}} \\
& & \sigma_{\alpha_{2}}^{2} & \sigma_{\alpha_{2}, \alpha_{3}} & \sigma_{\alpha_{2}, \alpha_{4}} \\
& & & \sigma_{\alpha_{3}}^{2} & \sigma_{\alpha_{3}, \alpha_{4}} \\
& & & & \sigma_{\alpha_{4}}^{2}
\end{array}\right]\right)
$$

Based on the final selected model, there are 8 soil and 3 PC indices identified from NRRMs3.1.1, and 20 PC indices from NRRMs-1.2 (Table 2). These indices can be translated as PC indices together with soil indices at the late vegetative stages (phases before tasseling with GDD increments of 200 and 400 from tasseling GDD) from NRRMs-3.1.1; PC indices in early vegetative stages (phase before tasseling with GDD increment of 1100 from tasseling GDD), midvegetative (phase before tasseling with GDD increment of 700 from tasseling GDD), late vegetative (phases before tasseling with GDD increments of 100, 200, and 400 from tasseling GDD), tasseling, silking, and throughout grain filling stages (phases after silking). These selected indices can be considered as potential causal factors for GEI in this MET study.

\section{Summary}

As a primary objective of the analysis, the potential causal factors of GEI for this unreplicated MET study were identified by estimating GEI using the proposed nested random regression models. These causal factors include both soil and weather indices from specific growth stages of the crop. The soil indices were organic matter content, cation exchange capacity, texture of soil, water holding capacity, depth of water table, and slope. The weather characters such as solar temperature, solar radiation, precipitation, wind velocity, atmospheric pressure, humidity, and evapotranspiration were identified from early vegetative, midvegetative, late vegetative, tasseling, silking, and throughout the grain filling phases. It should also be noted that our approach revealed potential causal weather indices as obtained not just from the PCs explaining highest percentage of variation. Considering the physiology of the crop, abiotic stresses on the phases identified, except the later grain filling stages, are critical to the reduction in yield (Grant, 1987; Kiniry et al., 1983; McWilliams et al., 1999). Variation in the weather characteristics during these stages, across locations with diverse soil characteristics, can be considered as the cause of variation in performance.

Thus far in the commercialization of newly developed hybrids, regions were identified based on the geographical proximity of the locations which may not be similar in their environmental characteristics, and then the hybrids are released to locations in each such region. Due to the influence of environment on hybrid genotypes, their performance can vary within a region. To alleviate this issue, our ongoing research will utilize the selected indices identified by our new method to identify locations similar in environmental characteristics to facilitate better allocation of hybrids to maximize homogeneous net production. . 
Table 1: Environmental factors that are used in modeling GEI.

\begin{tabular}{ll}
\hline Daily weather variables & Soil physical characteristics \\
\hline Temperature (max, min, avg, soil, and wind chill) & Organic matter content \\
Precipitation & $\mathrm{pH}$ \\
Atmospheric pressure & Cation exchange capacity \\
Evapotranspiration & Texture (sand, silt, and clay) \\
Wind speed (max, and avg) & Water holding capacity \\
Humidity & Depth of water table \\
Solar radiation (max, and avg) & Slope \\
\hline Note: maximum (max), minimum (min), average $(\mathrm{avg})$.
\end{tabular}

Table 2: Selected environmental indices from ${ }^{\mathrm{a}}$ NRRMs-3.1.1 and 1.2.

\begin{tabular}{|c|c|c|c|}
\hline \multicolumn{4}{|l|}{ NRRMs-3.1.1 } \\
\hline & Environmental indices & Phase of the crop & ${ }^{\mathrm{b}}$ GDD increment value \\
\hline \multirow{2}{*}{$\begin{array}{l}\text { Weather } \\
\text { indices }\end{array}$} & ${ }^{\mathrm{c}} \mathrm{PC} 6$ & \multirow{2}{*}{ Before tasseling } & 200 \\
\hline & PC 5 and 9 & & 400 \\
\hline \multirow[t]{8}{*}{ Soil indices } & Organic matter content & & \\
\hline & Cation exchange & & \\
\hline & capacity & & \\
\hline & Texture (sand, silt, and & & \\
\hline & clay) & & \\
\hline & Water holding capacity & & \\
\hline & Depth of water table & & \\
\hline & Slope & & \\
\hline \multicolumn{4}{|l|}{ NRRMs-1.2 } \\
\hline \multirow{13}{*}{$\begin{array}{l}\text { Weather } \\
\text { indices }\end{array}$} & PC 11 & Silking & \\
\hline & PC 2, 3, and 7 & \multirow{6}{*}{ After silking } & 100 \\
\hline & PC 1 and 5 & & 200 \\
\hline & PC 1 & & 300 \\
\hline & PC 5 & & 400 \\
\hline & PC 7 & & 500 \\
\hline & PC 2 & & 600 \\
\hline & PC 3 and 6 & Tasseling & \\
\hline & PC 12 & \multirow{5}{*}{ Before tasseling } & 100 \\
\hline & PC 6 & & 200 \\
\hline & PC 5, and 9 & & 400 \\
\hline & PC 8 & & 700 \\
\hline & $\mathrm{PC} 1,4$, and 7 & & 1100 \\
\hline
\end{tabular}

Note: ${ }^{a}$ NRRMs - Nested Random Regression Models, ${ }^{b}$ GDD - Growing Degree Days, ${ }^{c}$ PC Principal Component 


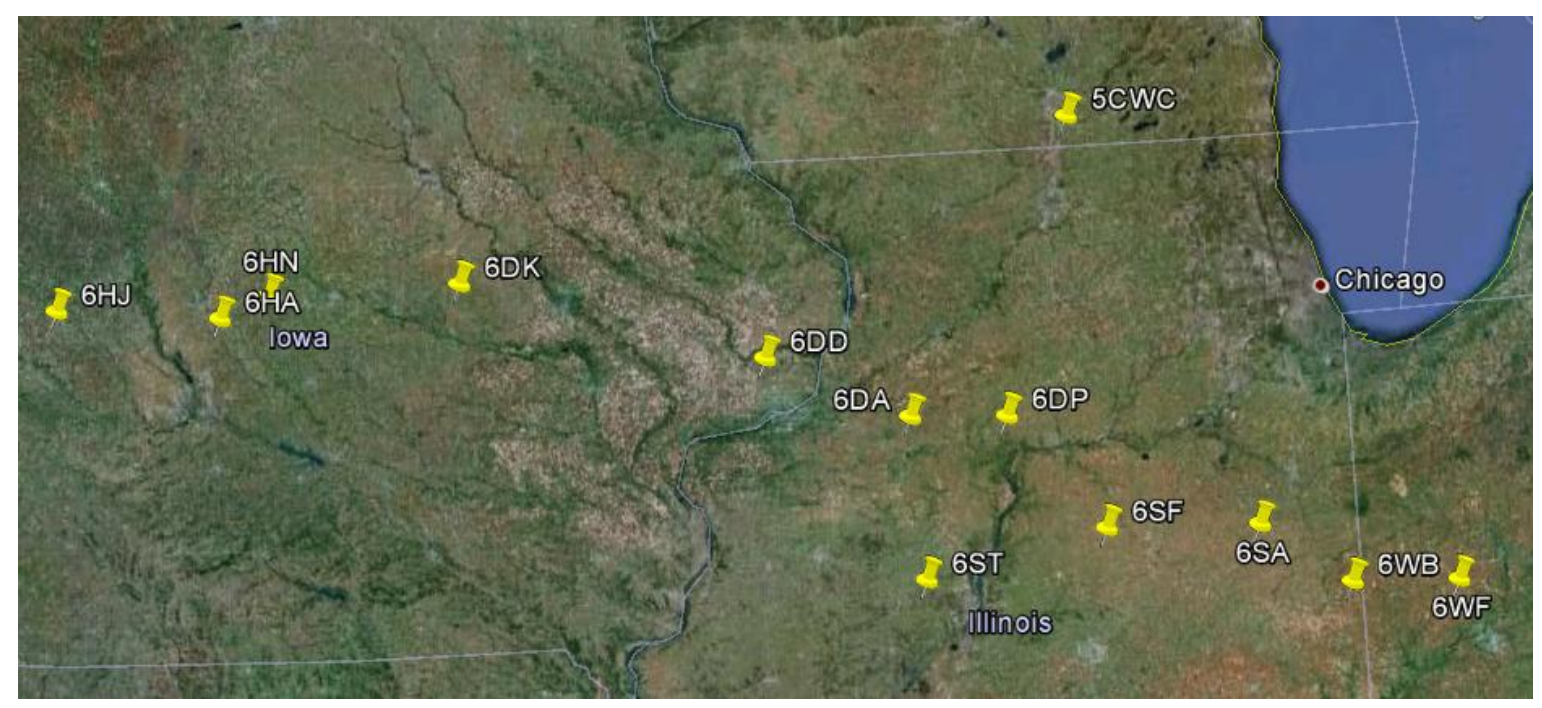

Figure 1: Distribution of locations across four states from the MET conducted in the Corn Belt. Locations are coded and their relative geographical positions are pinpointed.

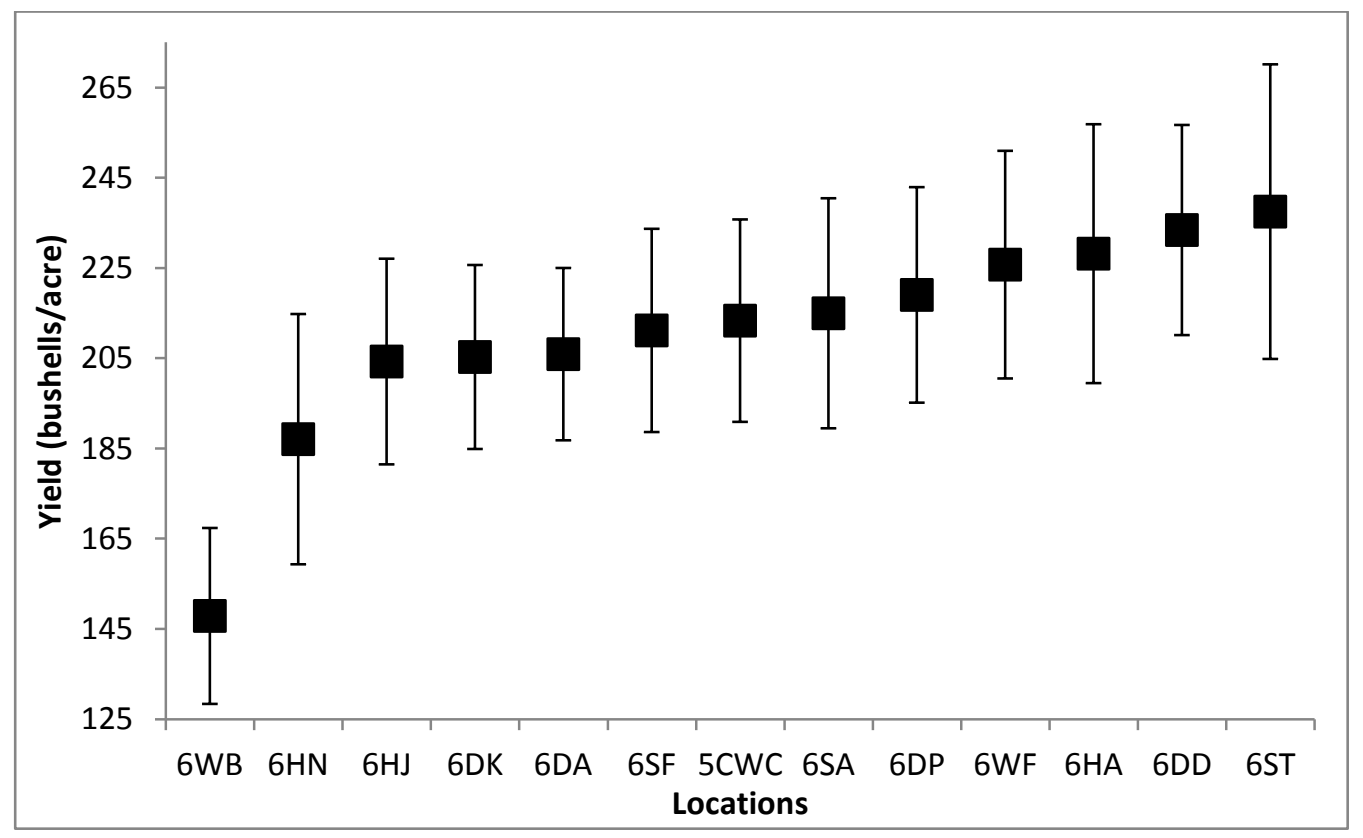

Figure 2: Yield averages of hybrids at each location along with their standard deviation from the MET study. The locations are arranged from left to right in the ascending order of yield averages. The same set of hybrids performed differently in different locations due to potential influence of location and GEI. 


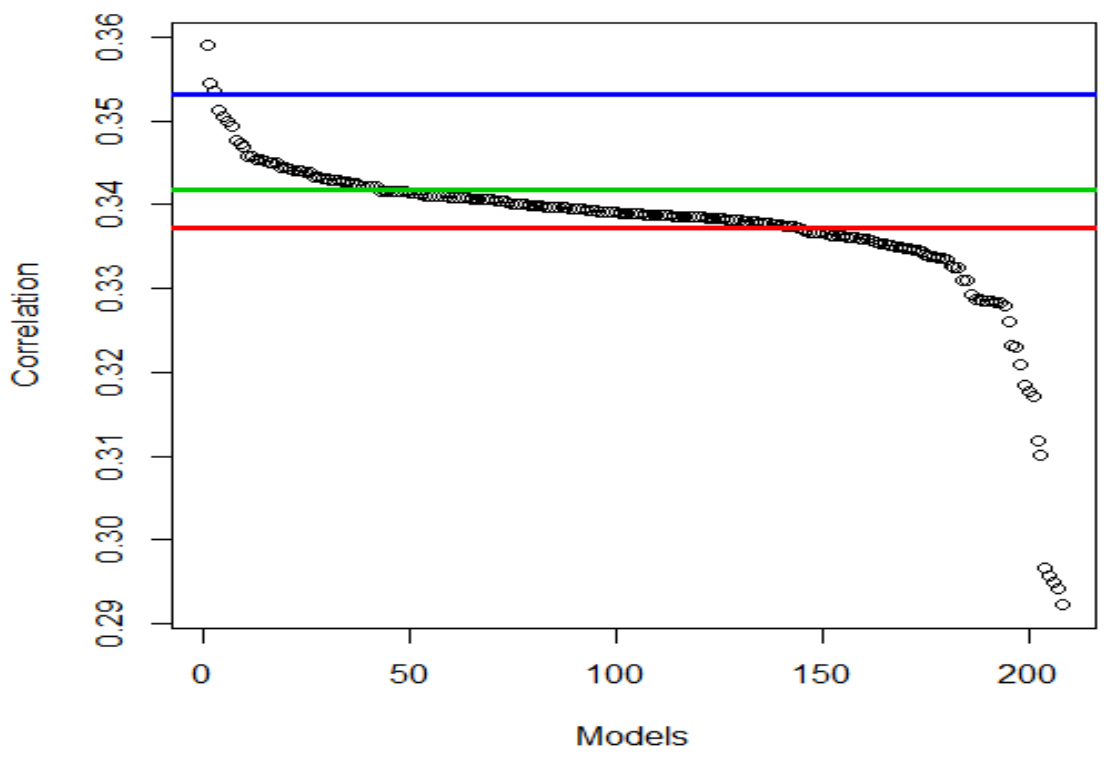

Figure 3: Correlation of predicted response of hybrids and GEI with observed response for 208 NRRMs-1.2 models. The red line indicates the threshold level from the base model, green from NRRMs-1.1, and dark blue from NRRMs-3.1. Thirty six models exhibited higher predictability than that of the highest NRRMs-1.1 and three of these models had higher predictability than that of NRRMs-3.1.

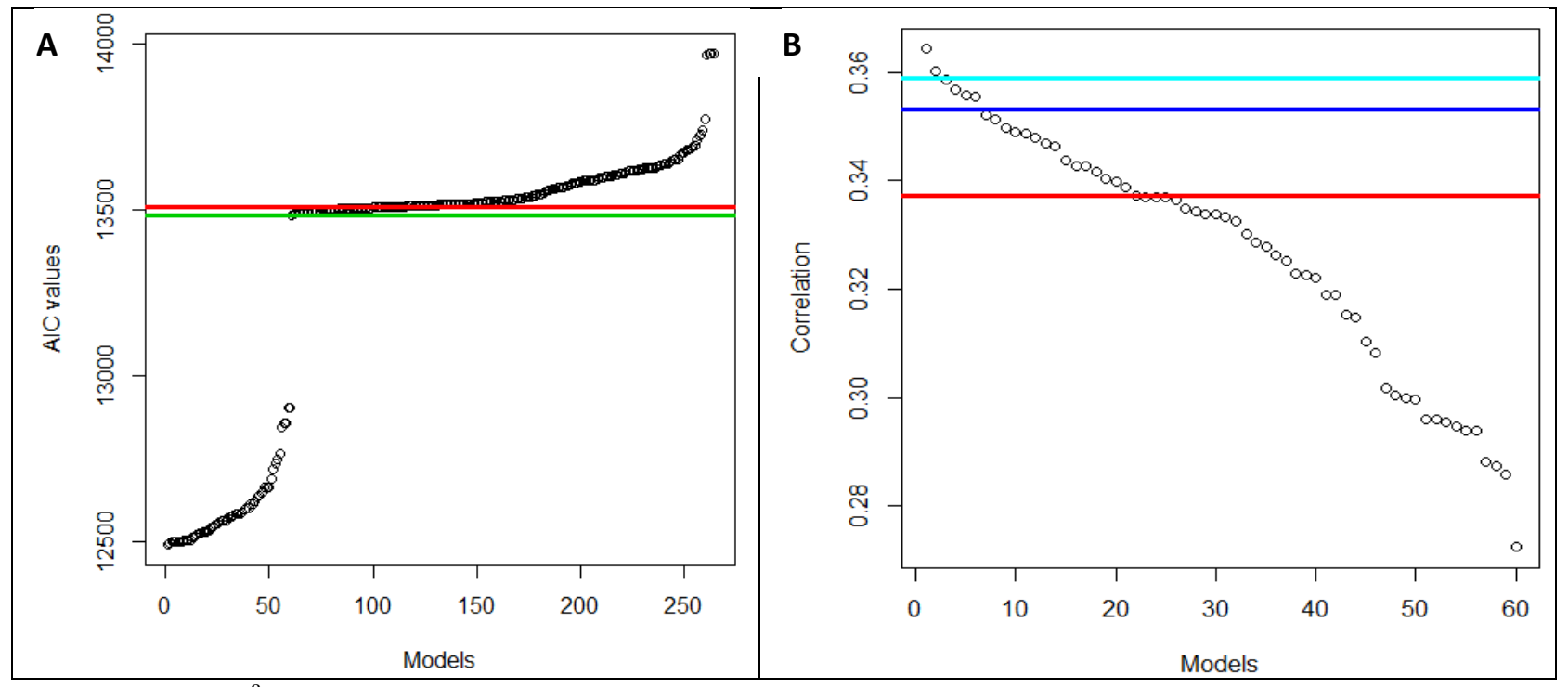

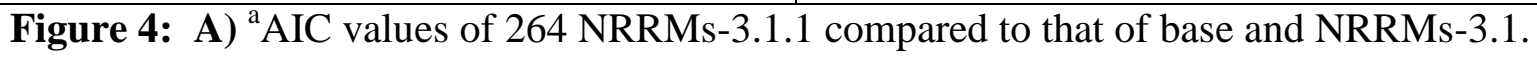
After comparison, 60 models were selected for predictability test. B) Correlation test of 60 selected NRRMs-3.1.1. Six NRRMs-3.1.1 exhibited predictability higher than that of NRRMs3.1 and two of them were higher than that of NRRMs-1.2. The light blue line indicates threshold level from NRRMs-1.2.

Note: ${ }^{\mathrm{a}} \mathrm{AIC}$ - Akaike Information Criteria 


\section{References:}

Aastveit A.H., Martens H. (1986) ANOVA interactions interpreted by partial least squares regression. Biometrics 42:829-844.

Baril C.P. (1992) Factor regression for interpreting genotype-environment interaction in breadwheat trials. Theoretical and Applied Genetics 83:1022-1026.

Bates D., Maechler M. (2010) Package 'Ime4', http://cran.rproject.org/web/packages/lme4/lme4.pdf.

Brown M.W. (2000) Cross-validation methods. Journal of Mathematical Psychology 44:108:132.

Cornelius P.L., Crossa J., Seyedsadr M.S. (1996) Statistical test and estimators of multiplicative models for genotype-by-environment interaction in: M. S. Kang and H. G. Gauch (Eds.), Genotype-by-environment interaction, CRC Press, Boca Raton, FL. pp. 199-234.

Dayton M.C. (2003) Model comparisons using information measures. Journal of Modern Applied Statistical Methods 2:281-292.

Dwyer L.M., Stewart D.W., Carrigan L., Ma B.L., Neave P., Balchin D. (1999) Guidelines for comparisons among different maize maturity rating systems. Agron J 91:946-949.

Eberhart S.A., Russell W.A. (1966) Stability parameters for comparing varieties. Crop Sci 6:3640.

FAO. (2009) FAOSTAT http://faostat.fao.org, Statistics Division, Food and Agriculture Organization of the UN.

Federer W.T. (1961) Augmented designs with one-way elimination of heterogeneity. Biometrics 17:447-473.

Federer W.T. (2002) Construction and analysis of an augmented lattice square design. Biometrics 44:251-257.

Federer W.T., Raghavarao D. (1975) On augmented designs. Biometrics 31:29-35.

Federer W.T., Rehnolds M., Crossa J. (2001) Combining results from augmented designs over sites. Agron J 93:389-395.

Finlay K.W., Wilkinson G. (1963) The analysis of adaptation in plant-breeding programme. Australian Journal of Agricultural Research 14:742-754.

Gauch H.G. (1992) Statistical analysis of regional yield trials. Elsevier, Amsterdam.

Gauch H.G., Zobel R.W. (1996) AMMI analysis of yield trials, in: M. S. Kang and H. G. Gauch (Eds.), Genotype-by-environment interaction, CRC Press, Boca Raton. pp. 416.

Henderson J., Charles R. (1982) Analysis of covariance in the mixed model: higher-level, nonhomogeneous, and random regressions. Biometrics 38:623-640.

Kang M.S., Gorman D.P. (1989) Genotype x environment interaction in maize. Agron J 81:662664.

Martin F.W. (1989) Maize, Echo technical note, Myers, FL. pp. 7.

Piepho H.P. (1997) Analyzing genotype-environment data by mixed models with multiplicative terms. Biometrics 53:761-766.

Signor C.E.-L., Dousse S., Lorgeou J., Denis J.-B., Bonhomme R., Carolo P., Charcosset A. (2001) Interpretation of genotype environment interactions for early maize hybrids over 12 years. Crop Sci 41:663-669. 
Smith A., Cullis B., Thompson R. (2001) Analyzing variety by environment data using multiplicative mixed models and adjustments for spatial field trend. Biometrics 57:11381147.

Smith A.B., Cullis B.R., Thompson R. (2005) The analysis of crop cultivar breeding and evaluation trials: an overview of current mixed model approaches. Journal of Agricultural Sciences 143:449-462.

van Eeuwijk F.A., Keizer L.C.P., Bakker J.J. (1995) Linear and bilinear models for the analysis of multi-environment trials: II. An application to data from the Dutch maize variety trials. Euphytica 84:9-22.

Warrington I.J., Kanemasu E.T. (1983) Corn growth response to temperature and photoperiod I. Seedling emergence, tassel Initiation, and anthesis. Agron J 75:749-754.

Williams E.R., John J.A. (2003) A note on the design of unreplicated trials. Biometrics 45:751757.

Yan W., Hunt L.A. (2001) Interpretation of genotype environment interaction for winter wheat yield in Ontario. Crop Sci 41:19-25.

Zobel R.W., Wright M.J., Gauch H.G., Jr. (1988) Statistical analysis of a yield trial. Agron J 80:388-393. 